\title{
Psychiatry in scripture: sacred texts and psychopathology
}

\author{
Christopher C. H. Cook ${ }^{1}$
}

The Psychiatrist (2012), 36, 225-229, doi: 10.1192/pb.bp.111.036418

'Department of Theology and Religion, Durham University, UK

Correspondence to Christopher C. H. Cook (c.c.h.cook@durham.ac.uk)

First received 11 Aug 2011, final revision 23 Dec 2011, accepted 30 Jan 2012
Summary The engagement of psychiatry with religion is increasingly important for better understanding of the ways in which religious people find resources to cope with mental disorder. An example of how a more critical and constructive engagement might be achieved is found in the psychiatric literature on sacred texts. Articles which engage with the alleged psychopathology of the 6th-century BC Hebrew prophet Ezekiel are examined as an example of this and proposals are made for a more critical yet sensitive and constructive future debate.

Declaration of interest C.C.H.C. is Chair of the Spirituality and Psychiatry Special Interest Group (SPSIG) at the Royal College of Psychiatrists. The views expressed in this article are his own. The SPSIG does not adopt any particular position in relation to the matters debated in this article, but welcomes open debate about this and other matters related to spirituality and psychiatry, both in publication and at its meetings. C.C.H.C. is an Anglican priest, and is Director of the Project for Spirituality, Theology and Health at Durham University.
Spirituality and religion refer to important aspects of human self-understanding, within the context of which many people find meaning and purpose in life, as well as resources to cope with illness and adversity. Although there is appropriate debate as to the proper boundaries and nature of good practice, ${ }^{1}$ psychiatric research and practice are increasingly directed towards better understanding of spirituality and religion in response to the expressed wishes of service users and to achieve better outcomes following treatment. ${ }^{2}$

A series of short articles published in the British Journal of Psychiatry, 'Psychiatry in the Old Testament', brings the perspectives of modern psychiatry to bear upon a number of ancient texts which are regarded as scripture within the Jewish and Christian traditions. This series offers reflections which identify speech, experiences, beliefs or behaviours indicative of a mental disorder on the part of either the author of the text or a person or persons referred to within. Where this involves an assertion that religious experiences are based on psychopathology, it reinterprets perceived human encounters with the divine as illusory or delusional. Diagnoses are offered in relation to people who lived millennia ago and who, in most cases, do not seem to have been considered as experiencing any kind of illness within the communities to which they belonged. These articles offer, but miss, an important opportunity to engage psychiatry in a critical and constructive way with religious texts that provide an understanding of how human beings tell the story of their existence in relation to a perceived transcendent reality.

\section{'Psychiatry in the Old Testament'}

To date, there have been 14 contributions to this series, ${ }^{3-16}$ which together address texts drawn principally from 6 (and to a lesser extent 3 more) out of 39 books in the Old Testament canon as acknowledged by Protestant Christian churches, and none of the deuterocanonical books acknowledged by the Roman Catholic and Orthodox churches.

The signs and symptoms of mental disorder identified within these texts include depressed mood, elation, drunkenness and other alcohol-related phenomena, failure to conform to social norms, impulsivity, irritability, jealousy and aggression. In the case of Ezekiel, the voice of God is identified as an auditory hallucination or thought insertion, and as being associated with passivity phenomena and catatonia. The psalmist who reflects on the suffering he experiences at the hands of his enemies is described as experiencing 'at least in some instances... paranoid ideation or possibly even paranoid delusions rather than real enemies.' ${ }^{13}$

The psychiatric diagnoses identified on the basis of these signs and symptoms include conduct disorder (in Proverbs and Deuteronomy), morbid jealousy (in Numbers), schizophrenia (in Ezekiel), depression and cyclothymia or bipolar disorder (in 1 Samuel and Psalms), borderline, antisocial and other personality disorders and alcohol dependence (in Proverbs). The diagnoses are confidently asserted (e.g. 'quite a good description', ' it is likely that ..., 5 'probably sufficient depressive symptomatology here to diagnose, ${ }^{\text {ll }}$ ). In only one article is there a clear note of caution: 'it may be all too easy to misinterpret these ancient 
verses and read contemporary psychiatric meaning into verses primarily spiritual and religious in their intent'. ${ }^{15}$

The direction of reflection is always that of psychiatry on the ancient religious text. Religious insights into the practice of psychiatry are not offered. There is no reflection on ways in which psychiatry alone might provide an incomplete perspective on human experience, or on ways in which contemporary Jews, Christians or others might make religious sense of their mental ill health.

This series of articles is not dissimilar to various longer papers which have sought to show that the religious or mystical experiences of Jesus of Nazareth, Paul of Tarsus, Theresa of Avila, Joan of Arc and other historical figures all find their basis in pathological conditions such as temporal lobe epilepsy or schizophrenia. ${ }^{17-20}$ An impression is often left that diagnosed psychopathology invalidates the spiritual meaning of the experiences in question. In fact, this is not necessarily the case. ${ }^{21}$ However, the lack of exploration of the implications of such exercises might be taken to imply that the conclusion is self-evident. People do not hear the voice of God and never have done, the reader might understand, they merely have mental disorders.

\section{Ezekiel: evidence for schizophrenia}

The three articles on Ezekiel ${ }^{14-16}$ are an interesting focus for further study. Stein identifies evidence for four first-rank symptoms, catatonia (Ezekiel 3:25-26 and 4:4-8) and various hallucinatory experiences, all of which lead him to a diagnosis of schizophrenia. The first-rank symptoms are: ${ }^{15}$

- thought insertion ('Thus says the Lord GOD: On that day thoughts will come into your mind, and you will devise an evil scheme' (Ezekiel 38:10)) ${ }^{\mathrm{a}}$

- thought broadcast ('Then the spirit of the LORD fell upon me, and he said to me, "Say, Thus says the LORD: This is what you think, $\mathrm{O}$ house of Israel; I know the things that come into your mind", (Ezekiel 11:5))

- passivity phenomena ('And when he spoke to me, a spirit entered into me and set me on my feet; and I heard him speaking to me' (Ezekiel 2:2))

- third-person auditory hallucinations ('As for you, mortal, your people who talk together about you by the walls, and at the doors of the houses, say to one another, each to a neighbour, "Come and hear what the word is that comes from the LORD"' (Ezekiel 33:30)).

Stein gives further examples, of the 'voices that Ezekiel hears', ${ }^{16}$ including 'command hallucinations' (Ezekiel 3:3, 12:1-7), non-verbal and verbal auditory perceptions associated with visions (Ezekiel 1:23-24 \& 25 (incorrectly referred to in the article as being Ezekiel 1:33 and 12:5 respectively)), and other instances of God speaking, in two of which (Ezekiel 9:1 \& 5) the 'out loud' nature of the voice appears to be confirmed. In one instance (Ezekiel 8:18), Stein argues that Ezekiel is trying his best not to listen to the voices.

a. Quoted English translations of Ezekiel are all from the Holy Bible, New Revised Standard Version Bible, 1989.

\section{Psychiatry and biblical studies today}

Psychiatry and biblical studies both value objectivity. Psychiatry seeks objective criteria as a basis for its diagnoses and treatments. Although some of what must be accepted as objective evidence is necessarily somewhat subjective (another person's account of the thoughts that they observe within their own minds, for example), the aspiration is to be as objective as possible. Transcultural psychiatry acknowledges further that objectivity is especially vulnerable where a psychiatrist from one culture confidently asserts the abnormality of experiences, beliefs or behaviour of a person from another culture. Thus, determination of the abnormality of religious experiences, beliefs and behaviours requires reference to the cultural norms of the particular faith tradition and its local community, as well as to the self-understanding of the individual.

Whereas the Bible, like other sacred texts, is studied by people of faith who search within its pages for spiritual truth, wisdom and divine revelation, it is also a subject of academic study by scholars who, as historians, linguists, theologians and textual or literary critics, seek objective evidence concerning the world of the text and its appropriate interpretation. As most biblical texts have now been subjected to a considerable amount of academic study, there is much that we know (as well as much that we still do not know) about who wrote them, whom they were written about and for, and the cultural, historical and literary assumptions on which they were based. The description of books as belonging to the 'Old Testament' is one which contemporary academic scholarship in biblical studies would generally eschew. Preferred terminology would be Hebrew, or perhaps Judeo-Christian, scripture. The term 'Old Testament' is a Christian confession, implying that this body of scripture has to be understood in the light of a newer testament which supersedes it, or is at least a more recent revelation of divine truth which influences the interpretation of it.

Psychiatry can have no view on whether, for example, people actually do hear the voice of God. Such a question is a theological rather than a scientific one. Answers to it depend on the hermeneutics of human experience rather than on scientific explanations and do not hinge on the presence or absence of psychopathology, although they may need to take this into account.

\section{Ezekiel revisited}

Ezekiel was a Hebrew prophet living in the 6th century BC who is recorded as having predicted the fall of Jerusalem and the destruction of the temple (which took place in $586 \mathrm{BC}$ ) built there by Solomon. He came from a priestly family, descended from the chief priest Zadok, and is himself identified as a priest (Ezekiel 1:2) prior to assuming the prophetic role. In $597 \mathrm{BC}$, Jerusalem having fallen to the invading Babylonian army, he was deported, along with other leading figures in his community, to Babylon. He was married, and bereaved in $587 \mathrm{BC}$ at approximately the same time that Jerusalem fell again following a second siege. After this, the Jerusalem temple (which figures prominently 
in one of Ezekiel's visions) was destroyed by the invading forces.

The social and historical role of the prophet in ancient Hebrew society is a complex matter. On the one hand the authority of Ezekiel and other prophets was based on perceived personal experience of the divine, and often associated with ecstatic experience, but on the other hand it fulfilled an important social role in speaking out against injustice. ${ }^{22}$ The sacred texts that emerged as a legacy of this religious, historical and cultural phenomenon are thus as much about a recognised critique of rulers and society as they are about individual experience of the divine. The book of the prophesies of Ezekiel as included in the canon of Hebrew scripture includes oracles against Israel and Judah, oracles against foreign nations and oracles concerning the future flourishing of Israel. ${ }^{23}$ In addition to the strange recorded behaviour of the prophet, it includes shocking sexual imagery ${ }^{24}$ and accounts of a series of five visionary experiences. A 6th-century authorship, by Ezekiel, now seems to be widely accepted, but it has been argued that much of the book was not written by Ezekiel and that it originated several centuries after the death of the prophet. There is reason to believe that Ezekiel's original words have been heavily edited by others ${ }^{24,25}$ and thus there is doubt about the full extent to which this text is attributable to the historical figure.

Notwithstanding the reservations of 20th-century scholarship, it is generally acknowledged that Ezekiel was a significant and creative author who shaped both Jewish and Christian traditions and is recognised also as a prophet within Islam.

\section{Schizophrenia}

On critical analysis, Stein's evidence for the identification of first-rank symptoms of schizophrenia in Ezekiel is not convincing. The text alleged to provide evidence of thought insertion $^{15}$ (Ezekiel 38:10) actually does not describe thought insertion at all. It says nothing about thoughts experienced as 'inserted', as though by an external agency, but rather refers to thoughts coming into a mind in much the same way that we might say of any new idea or intention that 'it came into my mind' to do something. Thus it has also been translated: 'Here is the Lord Yahweh's message: That will be the time when you start thinking up a scheme. ${ }^{26}$ Even if this were an example of thought insertion, it would be a prediction that thought insertion will be experienced by the person to whom the prophecy is addressed, which is the prince Gog, of Meshech and Tubal, and not Ezekiel (see Ezekiel 38:1-3).

Evidence for thought broadcast is similarly lacking. ${ }^{15}$ The relevant text (Ezekiel 11:5) is a prophecy addressed to a third party, in this case the nation of Israel, and not Ezekiel himself. Here it is clear that it is God who knows the secret thoughts of the people of Israel $^{27}$ and not that these thoughts are experienced as having been 'broadcast' in such a way as would qualify for identification of this as a firstrank symptom. As Stein acknowledges, ${ }^{15}$ if God is understood as 'all-knowing' he will be expected to know people's thoughts.

The interpretation of Ezekiel 2:2 as providing evidence for passivity phenomena depends upon an understanding of what, or who, the 'spirit' might be that enters into Ezekiel. The reference is similar to others in Ezekiel, including references to a power that moves other living beings and inanimate objects, as well as Ezekiel himself (e.g. Ezekiel 1:21, 3:12 \& 14; see also Allen ${ }^{28}$ ). The Hebrew word translated here as 'spirit' is רןת (ruach). This can mean 'wind', 'breath of life', the divine spirit, or a spirit of prophetic experience. ${ }^{29}$ It is also possible that the reference is to a 'spirit' of vigour or courage ${ }^{30}$ None of these meanings of the word requires identification of passivity phenomena. The assertion of spiritual agency is within cultural and textual norms.

The supposed evidence for third-person auditory hallucinations $^{15}$ (Ezekiel 33:30) is actually the voice of God speaking directly to Ezekiel, telling him what others are saying about him. This is not a third-person voice. It might be an auditory hallucination, but the 'voice of God' is commonly reported (whether metaphorically or otherwise) in some communities in the absence of diagnosable psychiatric disorder ${ }^{31}$ and is an almost ubiquitous phenomenon in biblical texts. Its diagnostic significance here is highly debatable, to say the least.

Where Stein argues that Ezekiel is trying not to listen to the voices, ${ }^{16}$ the instance cited (Ezekiel 8:18) is actually a text which refers to God not listening to the people of Judah when they cry out to him and does not refer at all to Ezekiel not listening. References to the voices and non-verbal auditory phenomena associated with visions (Ezekiel 1:2325) are not unequivocally hallucinatory according to modern criteria and, if they were, it is not clear what their diagnostic significance might be.

The evidence for catatonia ${ }^{14}$ is based on references to Ezekiel lying speechless and bound with cords for two periods of time, one of 390 days and one of 40 days (Ezekiel 3:25-26 and 4:4-8). As Stein notes, there are various possible interpretations of these verses, ${ }^{27,30}$ notably that the cords may have been allegorical or else the literal bonds imposed by the captors who took him into exile. The 'signactions', which are found in Ezekiel (e.g. dumbness, lying on his side, swallowing a scroll) and in other prophets, have been a subject of considerable study and interest. ${ }^{32}$ It is not possible to be historically confident that they were actually performed, although it is clear that they form effective literary devices. Quite apart from this, Ezekiel $4: 4-8$ is a cause of significant debate among commentators. Zimmerli, for example, has asserted that this portion of the text was added by a later editor ${ }^{27}$ and that the book as a whole is structured according to a literary style which simply does not allow us to recover the underlying experiences and actions of the historical Ezekiel. Overall, the justification for taking these texts as evidence of psychopathology is, at least, highly dubious and the uncritical application of these texts to that purpose does not show cognisance of relevant scholarship.

Robust evidence that Ezekiel had schizophrenia is entirely lacking. Stein does not explore differential diagnoses, or evidence that the ancient texts refer to a form of prophecy which was understood as culturally and religiously normal, even if unusually challenging and dramatic. He does not examine whether the texts were actually written by Ezekiel or whether they provide a reliable account on which 
to base an assessment of psychopathology. He does not explore his interpretations of the text in the historical, theological, literary and cultural context of the society in which they originated. Much of the evidence offered in support of the diagnosis is based on misinterpretations of the texts from which it is drawn.

\section{Differential diagnosis}

Medical and psychological interpretations of Ezekiel date back at least as far as 1877, when August Klostermann proposed a diagnosis of catalepsy. ${ }^{33}$ As Stein notes, ${ }^{14}$ Jaspers and various other commentators since have considered the possibility that Ezekiel may have had schizophrenia. ${ }^{27,33}$ In an influential paper published in 1946, Edwin Broome argued (like Stein) that Ezekiel 3:25-26 and 4:4-8 provide evidence of catatonia and that elsewhere in the text there are numerous examples of hallucinatory experience. ${ }^{34}$ This paper aroused significant controversy at the time, and has continued to do so since. ${ }^{33,35}$ Cassem's response ${ }^{36}$ represents the most important medical deconstruction of the case for diagnosing schizophrenia. He notes that purely exegetical considerations should cause us serious concern as to whether we have any reliable psychiatric evidence at all on which to base a diagnosis. If we do, Cassem continues, then there is no particular reason for singling out Ezekiel. A whole series of biblical prophets and visionaries are equal or stronger candidates for psychopathology. Cassem also warns against arguments based on a priori presumptions that religious texts purporting to give an account of experiences of God must, by definition, be evidence of psychiatric abnormality.

Altschuler argues that Ezekiel might have had temporal lobe epilepsy. ${ }^{23}$ This diagnosis is supported by evidence of extreme religiosity, aggression, hypergraphia, altered sexual behaviour, pedantry and 'sticky personality' (Geschwind syndrome). Altschuler also considers (but excludes) possible diagnoses of schizophrenia, bipolar disorder, substance misuse and migraine. Various authors entertain a possible diagnosis of post-traumatic stress disorder. ${ }^{24,37,38}$ This seems to be based more on the devastating human context of the siege and conquest of Jerusalem and subsequent experiences of forced exile and servitude, rather than specific diagnostic evidence. However, Smith-Christopher draws attention to the battlefield imagery of Ezekiel's vision of the valley of bones and some of the 'sign-actions' (such as being bound), and the sense of detachment associated with the visions of the Jerusalem temple. ${ }^{38}$ Other commentators have either concluded that there is no evidence of psychopathology ${ }^{39,40}$ or else that it may be understood in psychoanalytic terms. Broome identifies a conflict between narcissistic and masochistic tendencies as the cause of psychosis. ${ }^{34}$ Halperin ${ }^{33}$ identifies in Ezekiel a fear of female sexuality and a negative transference towards male authority figures, which in turn is projected onto God. Van Nuys ${ }^{41}$ suggests that we must look at the prophetic message as a creative problem-solving process. Using Ezekiel as an example, he suggests that apparently abnormal prophetic experiences and behaviour can represent a realistic and creative grappling with serious social problems.

The biblical texts provide no basis for the assertion that Ezekiel was considered to be mentally unwell by his contemporaries. Hebrew prophets certainly were accused of madness, as the examples of Hosea (Hosea 9:7), Elisha (2 Kings 9:11) and Jeremiah (Jeremiah 29:26) demonstrate. We have no record that such assertions were levelled against Ezekiel. The response of the people is rather to assert that his vision relates to the distant future and not to events that are near at hand (Ezekiel 12:26). The sign-actions, and perhaps other aspects of Ezekiel's behaviour, are better understood within the cultural and historical context as a meaningful, rational and dramatic attempt to get people to listen to a prophetic message which they seemed intent on ignoring.

Critical psychiatric evidence for any particular conclusion is all but completely lacking. Scholarship within the field of biblical studies would suggest that extreme caution be exercised in respect of simplistic interpretations of particular texts as providing evidence of the actual thoughts, experiences or behaviours of the prophet. This is especially so where such evidence is employed to support conclusions alien to the original theological purpose for which the text was written and anachronistic to its cultural and literary traditions.

\section{Psychiatry and sacred texts}

Psychiatry is oriented towards the interpretation of human thoughts, experiences and behaviours for the particular purpose of diagnosing and treating mental disorder. It can only provide reliable interpretations where cultural context is taken into consideration. Where historical texts provide the diagnostic evidence, it is further necessary to consider the resources of academic scholarship associated with the study of these texts. Failure to do this leaves open the danger of reaching conclusions which do not stand up to critical scrutiny and which may lead religious people, particularly users of mental health services, to conclude that psychiatry is unsympathetic to the spiritual or religious quest and that experiences and texts associated with this quest will be interpreted by psychiatrists as evidence of pathology. This discourages people who might benefit from psychiatric help from seeking it. It also leaves the psychiatrist, who is less likely to be religious than his or her patient, ${ }^{42}$ with a misleading impression of how sacred texts came to be written and how they are interpreted today.

The book of Ezekiel is better understood as being an account of mystical experience than of psychopathology. ${ }^{43}$ More importantly, it is a text which is taken to be revelatory of spiritual and religious truth within at least two of the world's major faith traditions. This does not mean that it cannot be examined critically, and the wealth of scholarship associated with this book provides testimony to Jewish and Christian willingness to ask difficult questions of the text and its tradition. However, to use psychiatry to examine it uncritically, and to reach conclusions of a narrowly psychiatric kind, is a disservice to psychiatry and religion.

Perhaps 'Psychiatry in the Old Testament' could be continued in the British Journal of Psychiatry under a title such as 'Psychiatry and Sacred Texts', within which critical academic scholarship in theology and religious studies might be brought into engagement with contemporary psychiatry. Whereas this might bring the light of sciences 
allied to psychiatry to bear critically and respectfully on religious texts, it might also shed some helpful light from religious studies on the practice of psychiatry. A truly critical and interdisciplinary conversation of this kind might help to engage a mutually deeper understanding of both psychiatry and religion.

\section{Acknowledgement}

I am pleased to acknowledge helpful comments on this article received from my colleague Professor Robert Hayward.

\section{About the author}

Christopher C. H. Cook is Professorial Research Fellow at the Department of Theology and Religion, Durham University, Abbey House, Palace Green, Durham DH1 3RS, UK.

\section{References}

1 Cook CCH, Powell A, Sims A, Eagger S. Spirituality and secularity: professional boundaries in psychiatry. Ment Health Relig Cult 2011; 14: 35-42.

2 Cook C, Powell A, Sims A (eds). Spirituality and Psychiatry. RCPsych Publications, 2009

3 Stein G. Morbid jealousy may have been recognised in the Old Testament. Br J Psychiatry 2011; 198: 142.

4 Stein G. Early child psychiatry. Br J Psychiatry 2010; 197: 105

5 Stein G. Hannah: a case of infertility and depression. $\mathrm{Br} J$ Psychiatry 2010; 197: 492.

6 Stein G. The case of King Saul: did he have recurrent unipolar depression or bipolar affective disorder? Br J Psychiatry 2011; 198: 212

7 Stein G. Alcoholism in ancient Israel. Br J Psychiatry 2008; 193: 113.

8 Stein G. Was the scoundrel (belial) of the Book of Proverbs a psychopath? Br J Psychiatry 2009; 194: 33.

9 Stein G. The essa zarah, the strange women of the Book of Proverbs. Br J Psychiatry 2009; 195: 293.

10 Stein G. Lost in translation: the biblical classification of personality disorder. Br J Psychiatry 2008; 193: 337.

11 Stein G. Psalm 38: A man with major depression. Br J Psychiatry 2010; 196: 309.

12 Stein G. Did the author of Psalm 30 have cyclothymia or bipolar disorder? Br J Psychiatry 2009; 195: 550.

13 Stein G. Paranoia in the Psalms. Br J Psychiatry 2010; 197: 284.

14 Stein G. Did Ezekiel have catatonia? Br J Psychiatry 2008; 193: 253.

15 Stein G. Did Ezekiel have first-rank symptoms? Br J Psychiatry 2009 194: 551 .

16 Stein G. The voices that Ezekiel hears. Br J Psychiatry 2010; 196: 101.

17 Foote-Smith E, Bayne L. Joan of Arc. Epilepsia 1991; 32: 810-5.
18 Schweitzer A. The Psychiatric Study of Jesus: Exposition and Criticism. Beacon, 1948.

19 Fales E. Scientific explanations of mystical experiences. Part I: The case of St Teresa. Relig Studies 1996; 32: 143-63.

20 Landsborough D. St Paul and temporal lobe epilepsy. J Neurol Neurosurg Psychiatry 1987; 50: 659-64.

21 Cook CCH. Psychiatry and mysticism. Ment Health Relig Cult 2003; 7 149-63.

22 Lindblom J. Prophecy in Ancient Israel. Blackwell, 1967.

23 Altschuler EL. Did Ezekiel have temporal lobe epilepsy? Arch Gen Psychiatry 2002; 59: 561-2.

24 Kohn RL. Ezekiel at the turn of the century. Currents Biblical Res 2003; 2 9-31.

25 Joyce PM. Ezekiel: A Commentary. Continuum, 2009.

26 Allen LC (eds DA Hubbard, GW Barker, JDW Watts). Ezekiel 20-48. Word Books, 1990

27 Zimmerli W (eds FM Cross, K Baltzer, LJ Greenspoon). Ezekiel. Fortress Press, 1979.

28 Allen LC (eds DA Hubbard, GW Barker, JDW Watts). Ezekiel 1-19. Thomas Nelson, 1994.

29 Zimmerli W (eds PD Hanson, LJ Greenspoon). Ezekiel. Fortress Press, 1983.

30 Greenberg M (ed WF Albright). Ezekiel 1-20. Doubleday, 1983.

31 Dein S, Littlewood R. The voice of God. Anthropol Med 2007; 14: 213-28.

32 Davis EF (ed DM Gunn). Swallowing the scroll: textuality and the dynamics of discourse in Ezekiel's Prophecy. Almond Press, 1989.

33 Halperin DJ. Seeking Ezekiel: Text and Psychology. Pennsylvania State University Press, 1993.

34 Broome EC. Ezekiel's abnormal personality. J Biblical Lit 1946; 65: 27792.

35 Howie CG (ed R Marcus). The Date and Composition of Ezekiel. Society of Biblical Literature, 1950.

36 Cassem NH. Ezekiel's psychotic personality: reservations on the use of the couch for biblical personalities. In The Word in the World: Essays in Honor of Frederick L Moriarty (eds RJ Clifford, GW MacRae): 59-70. Weston College Press, 1973.

37 Bowen NR. Ezekiel. Abingdon, 2010.

38 Smith-Christopher DL. Ezekiel on Fanon's couch: a postcolonialist dialogue with David Halperin's Seeking Ezekiel. In Peace and Justice Shall Embrace: Power and Theopolitics in the Bible (eds T Grimsrud, LL Johns): 108-44. Pandora Press, 1999.

39 Bron B. Psychopathology and proclamation of the prophet Ezekiel: the phenomenon of prophetic ecstasy [in German]. Schweitz Arch Neurol Neurochir Psychiatr 1981; 128: 21-31.

40 Eichrodt W. Ezekiel. SCM Press, 1970

41 Van Nuys K. Evaluating the pathological in prophetic experience (particularly in Ezekiel). J Am Acad Relig 1953; 21: 244-51.

42 Cook CCH. The faith of the psychiatrist. Ment Health Relig Cult 2011; 14 9-17.

43 Hines HW. The prophet as mystic. Am J Semitic Lang Lit 1923; 40: 37-71. 